\title{
Expanded Bodipy Dyes: Anion Sensing Using a Bodipy Analog with an Additional Difluoroboron Bridge
}

2012

Vol. 14, No. 6 1528-1531

\author{
Ruslan Guliyev, ${ }^{\dagger}$ Seyma Ozturk, ${ }^{\ddagger}$ Ertan Sahin, ${ }^{\S}$ and Engin U. Akkaya ${ }^{\star, \dagger, \neq}$ \\ UNAM-National Nanotechnology Research Center, Bilkent University, Ankara 06800, \\ Turkey, and Department of Chemistry, Bilkent University, Ankara 06800, Turkey, and \\ Department of Chemistry, Ataturk University, Erzurum 25240, Turkey
}

eua@fen.bilkent.edu.tr

Received February 1, 2012

\section{ABSTRACT}

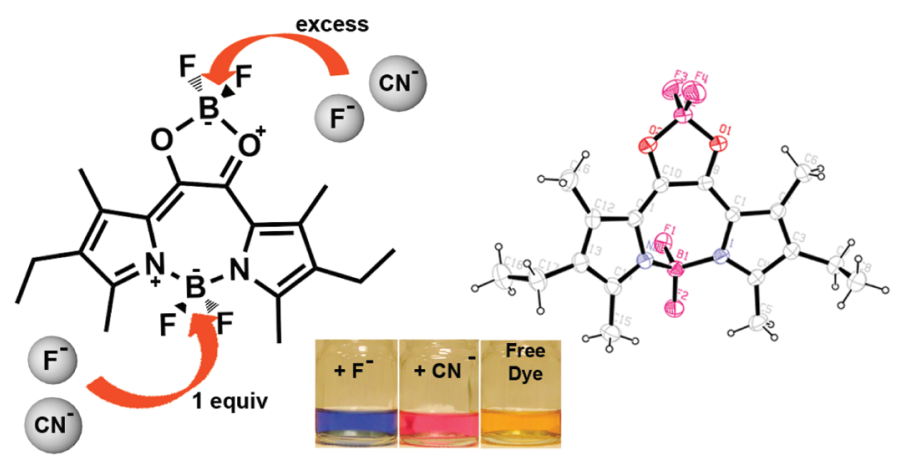

Oxalyl-tethered pyrroles can be doubly bridged with two difluoroboron chelating units to yield bright orange dyes. Interestingly, in polar organic solvents, the addition of fluoride and cyanide result in reversible detachment of the otherwise stable difluoroboron bridges, resulting in sharp changes in color. Thus, this novel compound behaves as a highly selective chromogenic sensor for fluoride and cyanide ions.

Within the past decade or so, Boron-dipyrrin (a.k.a., BODIPY, BDP, boradiazaindacene) dyes are experiemcing a bona fide renaissance after a two decade hiatus. ${ }^{1}$ This renewed interest is fueled by both new methodologies in derivatization and potential applications of these derivatives in ion sensing and signaling, ${ }^{2}$ energy transfer and light harvesting, ${ }^{3}$ photodynamic therapy, ${ }^{4}$ dye-sensitized solar cells, ${ }^{5}$ and nonlinear optical properties, ${ }^{6}$ to name just a few.

Once, just a class of fluorescent dyes limited by the repertoire of a single commercial supplier, ${ }^{7}$ Boron-dipyrrins are now being compared to porphyrins in diversity, scope, and function. The parent dye has been modified in many ways, including somewhat expanded versions, with pyridines instead of pyrroles being reported. ${ }^{\text {la }}$ The central six-membered ring, however, was not altered in any of these constructs. As a part of our ongoing efforts to diversify boron-dipyrrin applications and find novel tactics

\footnotetext{
UNAM-National Nanotechnology Research Center, Bilkent University.

Department of Chemistry, Bilkent University.

$\S$ Ataturk University.
}

of derivatization, we wanted to explore the effect of expanding the central chelate ring on absorption and fluorescence characteristics, in addition to potential signaling opportunities.

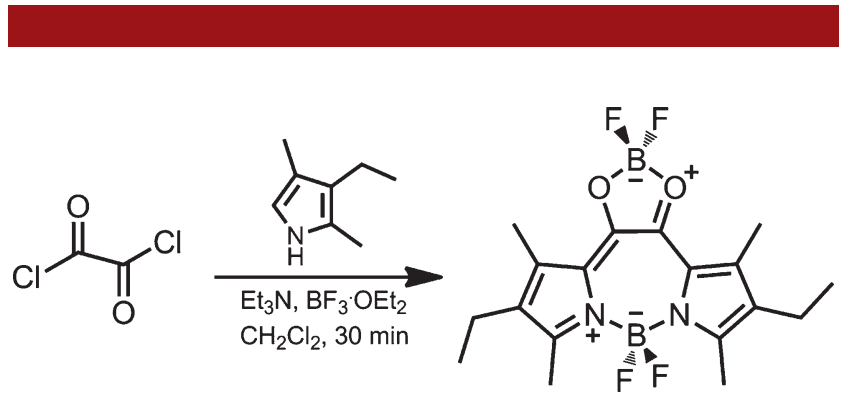

Figure 1. Synthesis of the target compound $\mathbf{1}$.

(1) (a) Loudet, A.; Burgess, K. Chem. Rev. 2007, 107, 4891-4932. (b) Ulrich, G.; Ziessel, R.; Harriman, A. Angew. Chem., Int. Ed. 2008, 47, 1184-1201. 
One promising path to an expanded central ring of the Boron-dipyrrin dyes was to tether two pyrroles with oxalyl chloride. To minimize any side reactions, we chose to start with a pyrrole with blocked reactive positions, i.e., 2,4dimethyl-3-ethylpyrrole. The reaction with oxalyl chloride proceeded smoothly, and without isolating the intermediate, we added $\mathrm{a} \mathrm{BF}_{3}$-etherate complex (Figure 1).

Following the usual workup, the major product turned out to be a nonfluorescent, bright red-orange product. While proton and carbon NMR spectra did not produce conclusive results, high resolution mass spectrometry (Supporting Information (SI)) and finally X-ray crystallography provided definitive information about the structure. The product was indeed an expanded core Borondipyrrin dye (Figure 2).

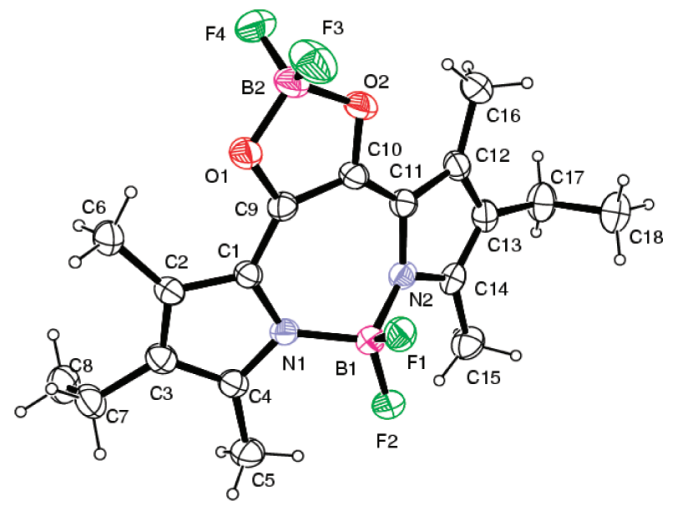

Figure 2. Ortep drawing of compound 1 . The $\mathrm{BF}_{2}$ bridge connecting two pyrroles is tilted out of planarity.

Single crystals suitable for $\mathrm{X}$-ray structure analysis were obtained by the slow evaporation of $\mathrm{CH}_{2} \mathrm{Cl}_{2}$ solutions at ambient temperature. The structure has some interesting features (SI): both boron bridges display distorted tetrahedral geometry, with somewhat unequal $\mathrm{B}-\mathrm{F}$ bond lengths and an $\mathrm{O}-\mathrm{B}-\mathrm{O}$ bond angle of $103.4^{\circ}$. The molecule is not planar, with an approximate torsion angle of $25.3^{\circ}$ for $B_{1}-N_{2}-C_{11}-C_{10}$. Thus, the expansion in the

(2) (a) Rurack, K.; Kollmansberger, M.; Resch-Genger, U.; Daub, J. J. Am. Chem. Soc. 2000, 122, 968-969. (b) Baruah, M.; Qin, W. W.; Vallee, R.; Beljonne, D.; Rohand, T.; Dehaen, W.; Boens, N. Org. Lett. 2005, 7, 4377-4380. (c) Coskun, A.; Akkaya, E. U. J. Am. Chem. Soc. 2006, 128, 14474-14475. (d) Sunahara, H.; Urano, Y.; Kojima, H.; Nagano, T. J. Am. Chem. Soc. 2007, 129, 5597-5604. (e) Yuan, M.; Li, Y.; Li, J.; Liu, X.; Lv, J.; Xu, J.; Liu, H.; Wang, S.; Zhu, D. Org. Lett. 2007, 9, 2313-2316. (f) Atilgan, S.; Ozdemir, T.; Akkaya, E. U. Org. Lett. 2008, 10, 4065-4067. (g) Hudnall, T. W.; Gabbai, F. P. Chem. Commun. 2008, 4596-4598. (h) Qi, X.; Kim, S. K.; Han, S. J.; Xu, L.; Jee, A. Y.; Kim, H. N.; Lee, C.; Kim, Y.; Lee, M.; Kim, S. J.; Yoon, J. Tetrahedron Lett. 2008, 49, 261-264. (i) Kennedy, D. P.; Kormos, C. M.; Burdette, S. C. J. Am. Chem. Soc. 2009, 131, 8578-8586. (j) Guliyev, R.; Coskun, A.; Akkaya, E. U. J. Am. Chem. Soc. 2009, 131, 9007-9013. (k) Guliyev, R.; Buyukcakir, O.; Sozmen, F.; Bozdemir, O. A. Tetrahedron Lett. 2009, 50, 5139-5141. (1) Bozdemir, O. A.; Guliyev, R.; Buyukcakir, O.; Selcuk, S.; Kolemen, S.; Gulseren, G.; Nalbantoglu, T.; Boyaci, H.; Akkaya, E. U. J. Am. Chem. Soc. 2010, 132, 8029-8036. (m) Yin, S. C.; Leen, V.; Van Snick, S.; Boens, N.; Dehaen, W. Chem. Commun. 2010, 46, 6329-6331. (n) Guliyev, R.; Ozturk, S.; Kostereli, Z.; Akkaya, E. U. Angew. Chem., Int. Ed. 2011, 50, 9826-9831.
Bodipy ring tilts the $\mathrm{BF}_{2}$ bridging two pyrrols above the plane defined by the rest of the molecule.

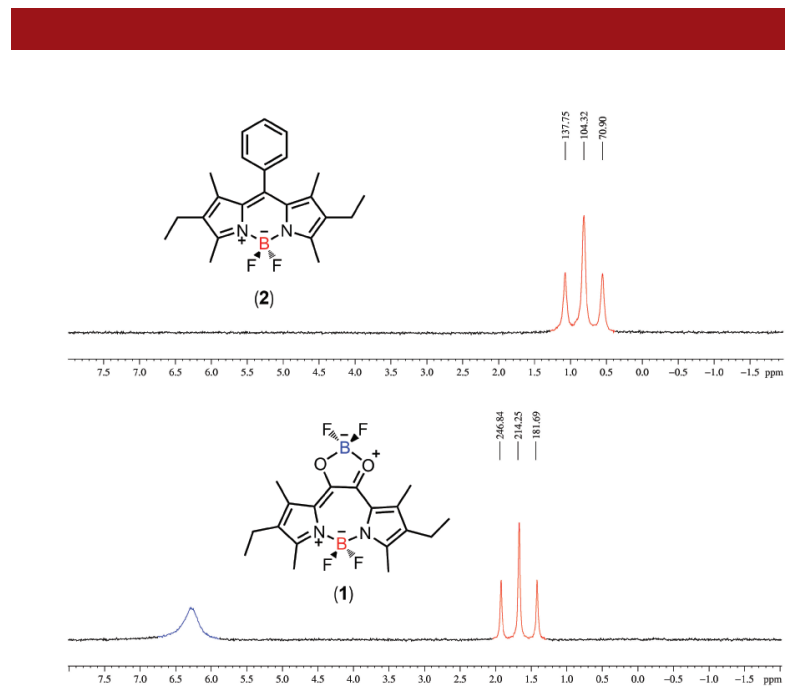

Figure 3. ${ }^{11} \mathrm{~B}$ NMR spectra of the reference (2) and the target compound (1) recorded in $\mathrm{CDCl}_{3}$ at room temperature. The expected triplet is observed which originates from the coupling between ${ }^{19} \mathrm{~F}(I=1 / 2)$ and ${ }^{11} \mathrm{~B}(I=3 / 2)$.

${ }^{11} \mathrm{~B}$ NMR is also highly informative; two distinct boron nuclei at $\delta 1.68 \mathrm{ppm}$ (internal reference $\mathrm{BF}_{3}-\mathrm{Et}_{2} \mathrm{O}$ ) and $6.30 \mathrm{ppm}$ are clearly identifiable. While one of the boron centers resonates as a triplet at $1.68 \mathrm{ppm}$, a broad peak at $6.30 \mathrm{ppm}$ is observed for the other boron nucleus (Figure 3$)$. The observed triplet originates from the coupling between ${ }^{19} \mathrm{~F}(I=1 / 2)$ and ${ }^{11} \mathrm{~B}(I=3 / 2)$. The $\mathrm{B}-\mathrm{F}$ $\left({ }^{11} \mathrm{~B},{ }^{19} \mathrm{~F}\right)$ coupling constants highly depend on the ligands bound to the boron nuclei. ${ }^{8}$

(3) (a) Zhang, X.; Xiao, Y.; Qian, X. Org. Lett. 2008, 10, 29-32. (b) Diring, S.; Puntoriero, F.; Nastasi, F.; Campagna, S.; Ziessel, R. J. Am. Chem. Soc. 2009, 131, 6108-6109. (c) Barin, G; Yilmaz, M. D.; Akkaya, E. U. Tetrahedron Lett. 2009, 50, 1738-1740. (d) Bozdemir, O. A.; Yilmaz, M. D.; Buyukcakir, O.; Siemiarczuk, A.; Tutas, M.; Akkaya, E. U. New J. Chem. 2010, 34, 151-155. (e) Bozdemir, O. A.; Cakmak, Y.; Sozmen, F.; Ozdemir, T.; Siemiarczuk, A.; Akkaya, E. U. Chem.-Eur. J. 2010, 16, 6346-6351.

(4) (a) Atilgan, S.; Ekmekci, Z.; Dogan, A. L.; Guc, D.; Akkaya, E. U. Chem. Commun. 2006, 4398-4400. (b) Erbas, S; Gorgulu, A.; Kocakusakogullari, M.; Akkaya, E. U. Chem. Commun. 2009, 49564958. (c) Ozlem, S.; Akkaya, E. U. J. Am. Chem. Soc. 2009, 131, 48-49.

(5) (a) Hattori, S.; Ohkubo, K.; Urano, Y.; Sunahara, H.; Nagano, T.; Wada, Y.; Tkachenko, N. V.; Lemmetyinen, H.; Fukuzumi, S. J. Phys. Chem. B 2005, 109, 15368. (b) Erten-Ela, S.; Yilmaz, D.; Icli, B.; Dede, Y.; Icli, S.; Akkaya, E. U. Org. Lett. 2008, 10, 3299. (c) Rousseau, T.; Cravino, A.; Bura, T.; Ulrich, G.; Ziessel, R.; Roncali, J. Chem. Commun. 2009, 1673. (d) Rousseau, T.; Cravino, A.; Bura, T.; Ulrich, G.; Ziessel, R. J. Mater. Chem. 2009, 19, 2298. (e) Forgie, J. C.; Skabara, P. J.; Stibor, I.; Vilela, F.; Vobecka, Z. Chem. Mater. 2009, 21, 1784. (f) Kolemen, S.; Cakmak, Y.; Erten-Ela, S.; Altay, Y.; Brendel, J.; Thelakkat, M.; Akkaya, E. U. Org. Lett. 2010, 12, 3812-3815. (g) Lee, C. Y.; Hupp, J. T. Langmuir 2010, 26, 3760.

(6) (a) Bouit, P. A.; Kamada, K.; Feneyrou, P.; Berginc, G.; Toupet, L.; Maury, O.; Andraud, C. Adv. Mater. 2009, 21, 1151-1154. (b) Zhang, D.; Wang, Y.; Xiao, Y.; Qian, S.; Qian, X. Tetrahedron 2009, 65, 80998103.

(7) Haugland, R. P. The Handbook - A Guide to Fluorescent Probes and Labeling Technologies, 10th ed.; Invitrogen Corp.: 2005.

(8) (a) Bernhardt, E.; Henkel, G.; Willner, H.; Pawelke, G.; Burger, H. Chem.-Eur. J. 2001, 7, 4696-4705. (b) Finze, M.; Bernhardt, E.; Willner, H.; Lehmann, C. Angew. Chem., Int. Ed. 2003, 42, 1052-1055. 
In comparison to a fairly typical Bodipy dye (compound 2), the peak which appears as a triplet can be assigned to the boron nucleus connected to the two pyrrole nitrogens (Figure 3). B-F coupling constants for the expanded Bodipy $\mathbf{1}$ and the model compound $\mathbf{2}$ are very similar (32.6 and $33.4 \mathrm{~Hz}$, respectively).

${ }^{19} \mathrm{~F}$ NMR is also supportive of the ${ }^{11} \mathrm{~B}$ NMR peak assignment (SI). The ${ }^{19} \mathrm{~F}$ NMR spectrum recorded for the target compound $\mathbf{1}$ displays two sets of nonequivalent fluorine atoms, one of which is a standard quartet signal (at $-132.5 \mathrm{ppm}$ ) that is also observed in the reference compound 2. The other one is a singlet at $-151.8 \mathrm{ppm}$, suggesting the presence of an oxygen atom adjacent to the boron bridge. ${ }^{10 \mathrm{c}}$ The other less intense singlet at $-151.7 \mathrm{ppm}$ is due to the less abundant NMR active ${ }^{10} \mathrm{~B}$ isotope $(20 \%)$. The isotope effect is also apparent for the fluoride atoms resonating as a quartet signal (at $-132.5 \mathrm{ppm})$. However, the septet originating from the ${ }^{10} \mathrm{~B}(I=3)$ isotope coupling is obscured under the quartet peak.

In hopes of creating a signal for the interaction of anions with the dye, we wanted to systematically study the spectral behavior of the solutions of $\mathbf{1}$ in the presence of selected anions. We suspected that one or both of the $\mathrm{BF}_{2}$ bridges might be reversibly disconnected concomitantly to a distinct spectral signature.

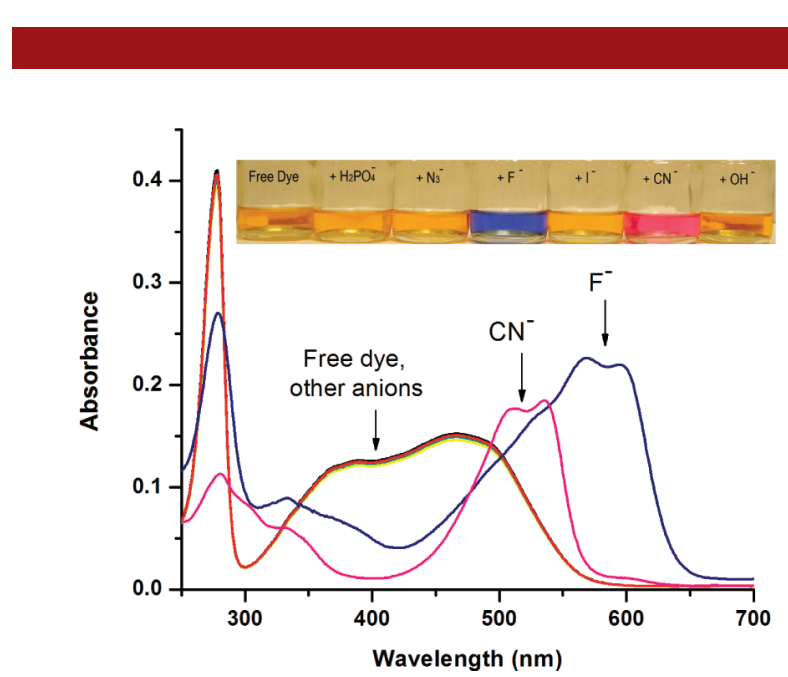

Figure 4. Absorbance spectra of target compound $\mathbf{1}(10.0 \mu \mathrm{M})$ in chloroform in the presence of several anions $(16.0 \mu \mathrm{M}$ for fluoride ion and $40.0 \mu \mathrm{M}$ for others). Inset: photograph of selected solutions under ambient light conditions in chloroform.

(9) (a) Jentsch, T. Curr. Opin. Neurobiol. 1996, 6, 303-308. (b) Varner, J. A.; Jensen, K. F.; Horwath, W.; Isaacson, R. L. Brain Res. 1998, 784, 284-298.

(10) (a) Kubo, Y.; Ishida, T.; Minami, T.; James, T. D. Chem. Lett. 2006, 35, 996-997. (b) Chawla, H. M.; Shrivastava, R.; Sahu, S. N. New J. Chem. 2008, 32, 1999-2005. (c) Hundnall, T. W.; Gabbai, F. P. Chem. Commun. 2008, 4596-4597. (d) Lam, S.-T.; Zhu, N.; Yam, V. W.-W. Inorg. Chem. 2009, 48, 9664-9670. (e) Hudnall, T. W.; Chiu, C. W.; Gabbai, F. P. Acc. Chem. Res. 2009, 42, 388-397. (f) Agou, T.; Sekine, M.; Kobayashi, J.; Kawashima, T. Chem. Commun. 2009, 1894-1896. (g) Sun, Y.; Wang, S. Inorg. Chem. 2009, 48, 3755-3767. (h) Lin, Y.-C.; Chen, C.-T. Org. Lett. 2009, 11, 4858-4861. (i) Xu, Z.; Kim, S. K.; Han, S. J.; Lee, C.; Kociok-Kohn, G.; James, T. D.; Yoon, J. Eur. J. Org. Chem. 2009, 3058-3065. (j) Bozdemir, O. A.; Sozmen, F.; Buyukcakir, O.; Guliyev, R.; Cakmak, Y.; Akkaya, E. U. Org. Lett. 2010, 12, 1400-
Rapid assesment of fluoride ion concentration in drinking water, consumer products, or the environment is important, considering th many detrimental health effects at elevated fluoride concentrations. ${ }^{9}$ This challenge has been addressed using many strategies, ${ }^{10}$ and colorimetric reagents are viable candidates for such analytic evaluations.

To explore the ion response of the expanded Bodipy compound 1, a careful analysis of anion promoted changes was carried out.

Thus, we added various anions in the form of TBA (tetrabutylammonium) salts into dilute chloroform solutions of 1. $\mathrm{CN}^{-}$ions also showed spectral changes, but the most obvious change was obtained with fluoride anions (Figure 4). The solution immediately turned purple on the addition of fluoride. Fluoride seems to be unique in generating such an intense spectral peak in the long wavelength region of the spectrum (at $600 \mathrm{~nm}$ ). $\mathrm{CN}^{-}$ions resulted in a less red-shifted peak near $520 \mathrm{~nm}$.

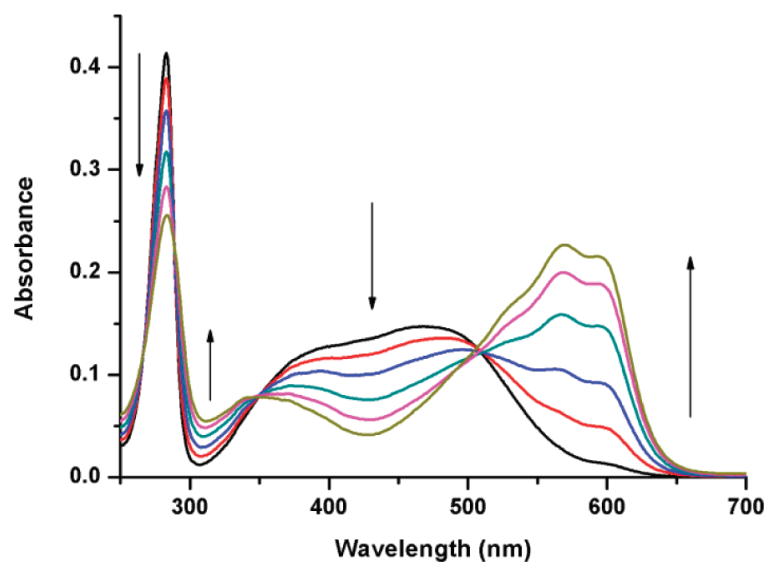

Figure 5. Titration of $\mathbf{1}(10.0 \mu \mathrm{M})$ with increasing fluoride (TBA salt) concentration $(0-16.0 \mu \mathrm{M})$ in chloroform.

Titration with varying concentrations of $\mathrm{F}^{-}$ions in the form of tetrabutylammonium salt in chloroform (Figure 5) clearly shows a progressive decrease of the broad band with a peak at $465 \mathrm{~nm}$. At the same time another set of peaks at longer wavelengths (565 and $600 \mathrm{~nm}$ ) appears.

A clean isosbestic point suggests a conversion between two distinct forms. The conversion is fast and reversible; the addition of $\mathrm{BF}_{3}-\mathrm{Et}_{2} \mathrm{O}$ in chloroform reverses the process, and the spectral features of compound $\mathbf{1}$ are restored. On closer inspection, we found out that excess $\mathrm{F}^{-}$ion addition gradually resulted a similar absorption peak around $520 \mathrm{~nm}$ while the longer wavelength peak disappears. Additional NMR and mass spectometric analysis suggest that, at lower concentrations of $\mathrm{F}^{-}$ion, initially, the $\mathrm{BF}_{2}$ unit bridging two pyrroles is detached. Higher concentrations result in the removal of the second $\mathrm{BF}_{2}$ unit in the form of $\mathrm{BF}_{4}{ }^{-}$.

1403. (k) Rao, M. R.; Mobin, S. M.; Ravikanth, M. Tetrahedron 2010, $66,1728-1734$. 

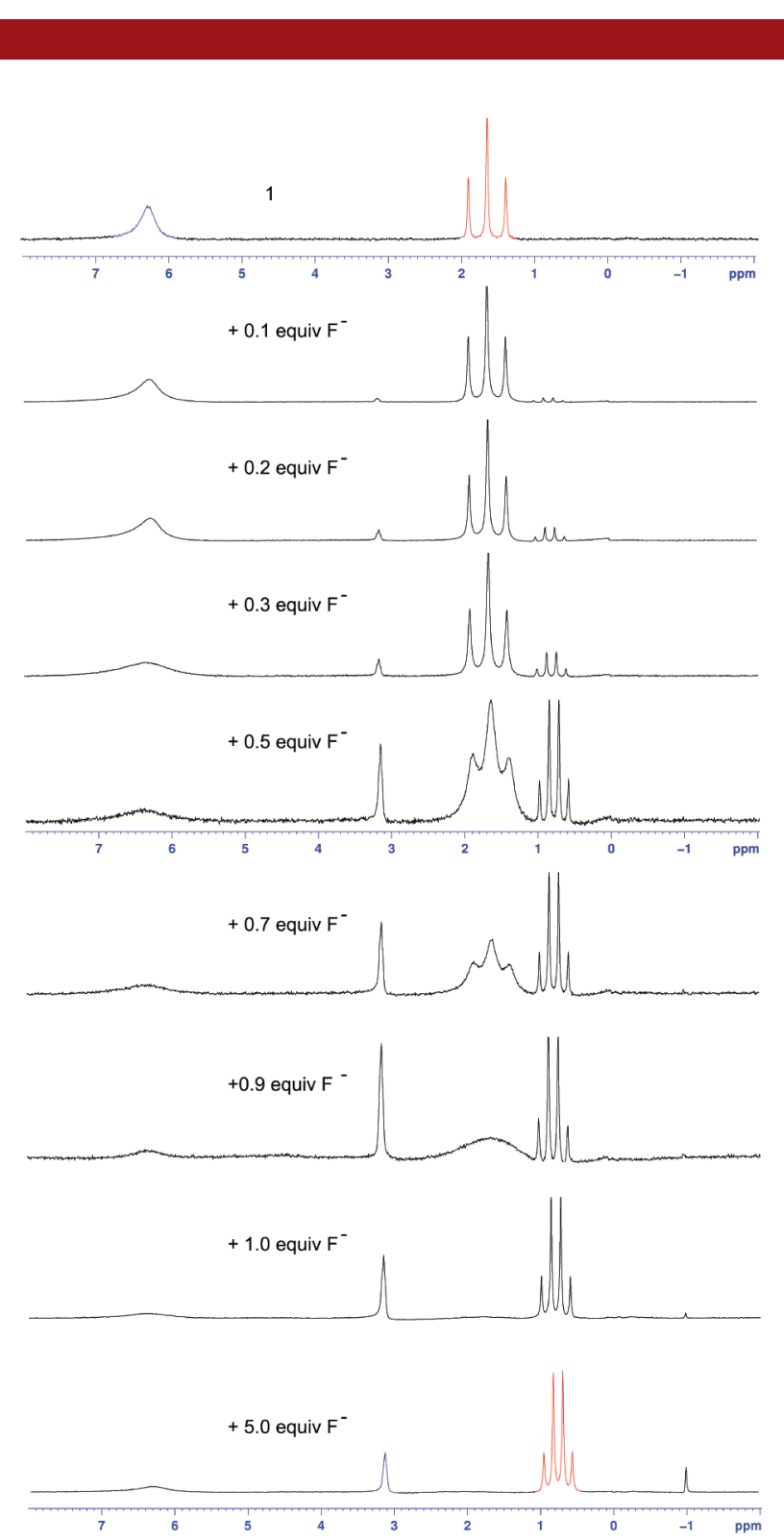

Figure 6. ${ }^{11} \mathrm{~B}$ NMR spectra of $\mathbf{1}$ after the addition of increasing concentrations of TBAF (recorded in $\mathrm{CDCl}_{3}$ at room temperature). The concentration of $\mathbf{1}$ is $12.6 \mathrm{mM}$.

Cyanide ions on the other hand do not discriminate between the two bridges; both linkages are attacked with comparable rates resulting in a red solution $(520 \mathrm{~nm})$. The same aborption peak and color form only with excess fluoride ions. Thus, both NMR spectra and absorption spectroscopy demonstrate that the differential reactivities of $\mathrm{CN}^{-}$and $\mathrm{F}^{-}$with two different boron centers is the reason for different absorbance signals.
Reference compound 2, a model Bodipy dye, showed no change in the ${ }^{11} \mathrm{~B}$ NMR spectrum upon addition of 100 equiv of fluoride anions (Figure 6). Being a part of the sixmembered ring makes the $\mathrm{sp}^{3}$ hybridized boron center less prone to nucleophilic displacement. It is unlikely for a fluoride anion to disrupt the ring through complexation with the central boron atom.

However, an expanded ring size (seven-membered ring) distorts the perfect tetrahedral structure of the boron bridge, making it more labile to fluoride attack. As a result, the gradual addition of fluoride ions lead to the decrease in the intensity of the $6.3 \mathrm{ppm}$ peak in ${ }^{11} \mathrm{~B} \mathrm{NMR}$, with a concomitant increase of two new singlet peaks at approximately 3.1 and $-1.0 \mathrm{ppm}$. Moreover, the triplet at $1.7 \mathrm{ppm}$ is transformed into a quartet with the new chemical shift at about $0.8 \mathrm{ppm}$ which can be assigned to a partially coordinated $\mathrm{BF}_{3}$ unit as shown in Figure $6(\mathrm{SI})$.

The singlet peak at $-1.0 \mathrm{ppm}$ proves the formation of free $\mathrm{BF}_{4}{ }^{-}$anions in the solution. ${ }^{11} \mathrm{~B}$ NMR of the reference compound tetrabutylammonium tetrafluoroborate confirms that the ${ }^{11} \mathrm{~B}$ nucleus in the tetrafluoroborate anion resonates at $-1.0 \mathrm{ppm}$ without any splitting (SI).

The broad singlet at $3.1 \mathrm{ppm}$ indicates the existence of the boron atom that is covalently attached to one of the oxygens in the molecule. Conversion of the triplet signal (at $1.7 \mathrm{ppm}$ ) to the corresponding quartet indicates the three neighboring fluorine nuclei splitting the boron peak into a quartet (at $0.8 \mathrm{ppm}$ ). Clear observation of the coupling constants suggests the existence of a covalent bond between boron and one of the pyrrole nitrogens.

Considering the need for simple colorimetric reagents for anion sensing, the novel expanded Bodipy dye described here is highly promising. The color changes are vivid, clearly distinguishing fluoride and cyanide ions in the presence of competing ions. Embedded to the polymeric matrix, this compound or a derivative is likely to find applications as anion sensors. In addition, further substitution on the Bodipy core is likely to broaden the palette of colors available in anion sensing. Our work in that direction is in progress.

Acknowledgment. Authors gratefully acknowledge support from TUBA (Turkish Academy of Sciences). R.G. and S.O. acknowledge support from TUBITAK-BIDEB in the form of a scholarship.

Supporting Information Available. Experimental procedures, structural proofs, additional spectral data for all new compounds, and CIF file for the crystallographic data for compound 1. This material is available free of charge via the Internet at http://pubs.acs.org.

The authors declare no competing financial interest. 